\title{
PREDAÇÃO DE NINHOS ARTIFICIAIS EM UM FRAGMENTO DE FLORESTA ESTACIONAL SEMIDECIDUAL NO OESTE DO ESTADO DO PARANÁ, BRASIL
}

\author{
Artificial nest predation in a fragmented forest \\ on west of Parana state, Brazil
}

\author{
Allan R. Tressi ${ }^{1}$ \\ Éderson M. Klein ${ }^{1}$ \\ Pedro A. Botin ${ }^{1}$ \\ Patrícia A. Nicola ${ }^{2}$
}

\section{Resumo}

A fragmentação de hábitats afeta as populações de aves, aumentando, dentre tantos fatores, as taxas de predação dos ninhos. Em um fragmento, de 2 ha, de Floresta Estacional Semidecidual no Estado do Paraná, a predação de ninhos artificiais foi observada por um período de 36 dias, entre os meses de setembro a outubro de 2003, com intervalos de dois dias. Neste experimento, foram distribuídos ninhos na borda e interior da mata e ovos de Coturnix coturnix japonica (codorna-doméstica) foram utilizados para simular a predação. Os resultados obtidos não apresentaram diferença significativa entre a área de borda e interior da mata, mas foi observada uma diferença significativa em relação à predação de ovos no solo e nos arbustos do fragmento. Os resultados sugerem que todo o fragmento estudado está sob efeito de borda.

Palavras-chave: Predação; Ninhos artificiais; Fragmentação; Efeito de borda.

\section{Abstract}

Habitats fragmentation affects the birds populations, increasing the rates nests predations. In an Semidecidual forest fragment, at Parana State, the predation of artificial nest was observed for a period of 36 days, with intervals of two days. In this experiment were distributed nests on the edge and inside forest fragment and eggs of Coturnix coturnix japonica (Japanese Quail) were used for predation simulation. The eggs predation showed no significant differences among the edge and inside forest, but was found a significant difference between ground and shrubs in the fragment. The results suggest that there is edge effect in this forest fragment.

Keywords: Predation; Artificial nest; Fragmentation; Edge effect.

Trabalho desenvolvido durante o Curso de Ecologia de Campo da Disciplina Ecologia Geral e Aplicada do Curso de Ciências Biológicas da PUCPR - Câmpus Toledo.

1 Acadêmicos do Curso de Graduação de Ciências Biológicas do Centro de Ciências, Tecnologia e Produção, Câmpus Toledo, Pontifícia Universidade Católica do Paraná.

2 Professora Assistente, Curso de Ciências Biológicas do Câmpus Universitário de Rondonópolis, ICEN, Universidade Federal de Mato Grosso. Rodovia Rondonópolis/Guiratinga, km 6, Bairro Sagrada Família, Rondonópolis, MT CEP 78735-901. patinicola@yahoo.com.br.1 


\section{Introdução}

Com o processo de colonização, a destruição das florestas tropicais tem avançado assustadoramente, transformando esses ecossistemas em pequenos fragmentos em poucas décadas (1). A fragmentação florestal resulta em uma variedade de efeitos físicos e biológicos, onde os padrões de dispersão e migração são interrompidos e as populações são reduzidas (2). As bordas dos fragmentos possuem condições ambientais, diferenciadas com altas taxas de mortalidade de árvores, permitindo o estabelecimento de espécies não florestais $(1,3)$. O efeito de borda, associado à fragmentação florestal, pode em alguns casos chegar a $500 \mathrm{~m}$ de distância em direção ao interior da floresta (1), favorecendo uma alteração na estrutura da floresta e refletindo na modificação da diversidade e abundância de muitas espécies de animais. Diversos estudos sugerem que muitas das mudanças associadas à fragmentação das florestas alteram as taxas de predação de ninhos das aves, e que a diminuição do tamanho do fragmento florestal resulta no aumento da predação de ninhos $(4,5)$. Estudos têm demonstrado que as taxas de predação nas bordas dos fragmentos florestais é maior do que no interior, sugerindo que os predadores selecionam as bordas dos fragmentos para forragear, aumentando a pressão de predação (6, $7,8,9)$. Entretanto, outros estudos não verificaram uma taxa maior de predação de ninhos localizados na borda dos fragmentos em relação ao interior $(10,11)$. A predação acumulada de ovos em um fragmento passa a exercer pressões sobre outras populações (12, 3). Melampy et al. (13) destacaram que a predação de ninhos poderia estar relacionada à alta densidade de mamíferos de médio porte, desta forma espécies de aves que nidificam no chão constituem o principal alvo de predação, principalmente em ambientes fragmentados, já que a área útil de floresta torna-se muito reduzida.

Neste trabalho, testou-se a hipótese de que existe efeito de borda em um fragmento de Floresta Estacional Semidecidual no município de Toledo, Estado do Paraná, mediante a observação da freqüência de remoção ou predação de ovos em dois hábitats previamente escolhidos, e avaliar a taxa de predação de ovos no estrato vertical, solo e dossel, buscando identificar onde ocorre maior predação.

\section{Material e métodos}

\section{Área de estudo}

O estudo foi realizado em um fragmento de Floresta Estacional Semidecidual do Câmpus da PUCPR (Pontifícia Universidade Católica do Paraná) (24 $45^{\prime} 25^{\prime \prime} \mathrm{S}-53^{\circ} 42^{\prime} 25^{\prime}$ ”W), situado no município de Toledo, Estado do Paraná, com área total de aproximadamente $48.000 \mathrm{~m}^{2}$. Localiza-se na Região Oeste do Estado, no terceiro planalto paranaense, a uma altitude de $574 \mathrm{~m}$ a.n.m. O solo é do tipo latossolo roxo, comumente chamado de terra roxa (14). O clima da cidade de Toledo é subtropical úmido-brando, com temperatura média anual de $23,1^{\circ} \mathrm{C}(15)$.

\section{Coleta de dados}

Para simular a predação foram utilizados 480 ovos de Coturnix coturnix japonica (codorna-doméstica) e 40 ninhos artificiais. Os ninhos foram dispostos em dois transectos, na borda e interior da floresta. Foram considerados ninhos de borda aqueles dispostos aproximadamente a $10 \mathrm{~m}$ da borda do fragmento de floresta, e ninhos de interior aqueles localizados a aproximadamente $50 \mathrm{~m}$ em direção ao interior do fragmento. Em cada transecto foram instalados 20 ninhos artificiais, sendo que destes, 10 estavam no solo e 10 em galhos de árvores. Cada ninho estava eqüidistante um do outro em $20 \mathrm{~m}$ e os ninhos das árvores foram colocados a uma altura média de $2 \mathrm{~m}$ do solo. Cada ninho foi numerado, e semanalmente, no período de 6 de setembro a 12 de outubro de 2003, foi feita disposição dos ovos nos ninhos. O monitoramento destes foi realizado durante dois dias consecutivos, sempre pela manhã (06h00). Para os ninhos onde os ovos foram removidos, foram repostos os ovos até o final de cada amostragem.

\section{Análise de dados}

A predação de ovos entre a borda e o interior do fragmento e entre os estratos (solo e árvores) foi comparada usando o teste de Quiquadrado (16). 


\section{Resultados}

Do total de 480 ovos utilizados, 227 ovos $(47,30 \%)$ foram predados. Quando comparada a probabilidade de predação entre os ambientes (borda $\mathrm{X}$ interior), observou-se que houve uma maior predação no interior do fragmento (119 ovos - 50\%) do que na borda (108 ovos - 45\%), porém esta diferença não foi significativa $\left(\chi^{2}=0,056 ; p=\right.$ 0,81 , n.s.). Quando comparada a probabilidade de predação entre estratos (solo $\mathrm{X}$ árvore), observou-se que houve uma diferença significativa $\left(\chi^{2}=13,88 ; \quad p<0,05\right)$, sendo observada uma maior predação no solo (201 ovos - 83,75\%) do que no dossel (26 ovos - 10,83\%). Não foram observadas diferenças significativas quando comparados os estratos (solo e árvore) com os ambientes (borda e interior) $\left(\chi^{2}=0,50 ; p=0,48\right)$.

\section{Discussão e conclusão}

Antunes et al. (17) estudaram a predação de ovos em um fragmento de Floresta Ombrófila Densa e verificaram que cerca de $64 \%$ dos ovos dispostos em ninhos artificiais foram predados, sendo a maior predação observada no interior do fragmento $(70,37 \%)$ do que na borda dele $(57,69 \%)$, não havendo diferença significativa entre os ambientes amostrados. Duca et al. (18), ao avaliarem a taxa de predação de ninhos artificiais em fragmentos em Minas Gerais, não observaram diferença significativa na predação de ninhos de borda e de interior, bem como dos ninhos dispostos em arbustos e no solo dos fragmentos. Keyser et al. (4), ao estudarem o efeito do tamanho do fragmento florestal na taxa de predação de ninhos, verificaram uma correlação negativa entre o tamanho do fragmento e a taxa de predação de ninhos, de modo que quanto menor o fragmento, maior era a taxa de predação, porém não encontraram evidências significativas do efeito de borda sobre a predação de ninhos. Os autores também verificaram que houve maior ação dos predadores com o aumento da fragmentação dos hábitats. Em contrapartida, os dados obtidos por Melo e Marini (19) não suportaram a hipótese de que a taxa de predação aumenta com a diminuição dos fragmentos. Small e Hunter (20) argumentam que o aumento nas taxas de predação de ninhos não se deve somente ao tamanho dos fragmentos, mas também a outros fatores, como a densidade e diversidade dos predadores.
Nossos resultados demonstraram que a predação aconteceu de forma similar nos dois ambientes testados, não havendo diferença significativa entre interior e borda do fragmento amostrado. Um estudo similar foi desenvolvido no Museu de Biologia Mello Leitão, no Espírito Santo, em que os autores verificaram que não há diferenças quando compararam as taxas de predação entre a borda e o interior da floresta (21). Isso pode estar relacionado com a redução do fragmento $(1,5)$, onde toda a área estudada está sob o efeito de borda. O mesmo foi constatado por Melo e Marini (19), que destacam que os fragmentos estudados não possuem área central isenta do efeito de borda e assim os predadores agem de forma uniforme em todo o fragmento.

Quando observada a predação em relação aos estratos (solo e árvore), verificou-se que a predação de ninhos no solo foi muito superior daqueles dispostos nas árvores, fato que pode estar relacionado ao maior número de predadores terrestres e não arborícolas. Nossos resultados são similares àqueles apresentados por Melampy et al. (13), que também observaram que as taxas de predação foram menores em estratos arbóreos (60\%) do que no solo (85\%). Roos (22) investigou os riscos da predação de ninhos e observou que existe relação positiva entre a densidade de ninhos e a predação deles, bem como maior predação de ninhos em áreas abertas do que em áreas florestadas. Martin e Joron (23) verificaram que o risco de predação varia no espaço e no tempo e com a qualidade do hábitat. Apesar de existir uma relação dependente da densidade, nossos resultados sugerem que a estratégia mais segura para reprodução de algumas aves em áreas fragmentadas e alteradas seja a construção dos ninhos em arbustos, já que a taxa de predação de ovos foi relativamente menor em relação ao solo. Os resultados apresentados ainda indicam que a maioria dos predadores são terrestres e, portanto, exercem grande influência sobre a predação dos ninhos colocados no solo, contribuindo com a redução da reprodução e a diversidade de espécies de aves terrestres. Contudo, cabe ressaltar que as taxas de predação não são influenciadas somente pelo tamanho do fragmento, mas também por fatores como: diversidade e densidade de predadores e características da vegetação em cada área estudada (20, 24, 25). 


\section{Referências}

1. Laurence WF. Edge Effects in Tropical Forest Fragments: Application of a Model for the Design of Nature Reserves. Biological Conservation. 1991; 57:205-219

2. Tabarelli M, Baider C, Mantovani W. Efeitos da fragmentação na floresta Attântica da bacia de São Paulo: Hoelmea. 1998; 25(2):169-186.

3. Tabarelli M, Mantovani W. Predação de ovos e remoção de propágulos em um fragmento de floresta Atlântica, ES- Brasil. Revista Brasileira de Biologia. 1997; 57(4):699-707.

4. Keyser A J, Hill GE, Soehren EC. Effetcs of forest fragment size, nest density, and proximity to edge on the risk of predation to ground-nesting passerine birds. Conservation Biology. 1998; 12(5):986-994.

5. Terborgh J. Why American songbirds are vanishing. Scientific American. 1992; 266:98-104.

6. Gates JE, Gysel LW. Avian nest dispersion and fledging success in field-forest ecotones. Ecology. $1978 ; 59: 871-883$

7. Andrén H, Angeltam P. Elevated predation rates as edge effect in habitat islands: experimental ecidence. Ecology. 1988; 69:544-547.

8. Burkey TV. Edge effects in seeds and predation at two neotropical rainforest sites. Biological Conservation. 1993; 66:139-143.

9. Wilcove DS Nest predation in forest tracts and the decline of migratory songbirds. Ecology. 1985; 66:1211-1214.

10. Melo C, Marini MA. Predação de ninhos artificiais em fragmentos de matas do Brasil Central. Ornitologia Neotropical. 1997; 8:7-14.

11. Leite, LO, Marini MA. The effects of forest fragmentation on predation rates of artificial bird nests in Minas Gerais. Ciencia e Cultura. 1999; 51:34-37.

12. Haegen WMV, DeGraaf RM. Predation rates on artificial nests in an industrial forest landscape. Forest Ecology and Management. 1996; 86:171-179.

13. Melampy MN, Kershner EL, Jones MA. Nest predation in suburban and rural woodlots of Northern Ohio. The American Midland Naturalist. 1999; 141(2):284-292.
14. Empresa Brasileira de Pesquisa Agropecuária. Centro Nacional de Pesquisa de Solos. Sistema Brasileiro de Classificação de Solo. Rio de Janeiro: [s.n.]; 1999. 412 p.

15. Toledo, Prefeitura Municipal. Toledo e seus distritos (repensando os distritos de Toledo). Toledo: Prefeitura Municipal; 1986.

16. Zar JH. Biostatistical analysis. Englewood Cliffs: Prentice Hall; 1984.

17. Antunes DF, Silva MAM, Albuquerque ALE. Predação de ovos em um fragmento de floresta Atlântica. Brasil. Biota. 2000; 1(1):14-18.

18. Duca C, Gonçalves J, Marini MA. Predação de ninhos artificiais em fragmentos de matas de Minas Gerais, Brasil. Ararajuba. 2001; 9(2):113-117.

19. Melo C, Marini MA. Predação de ninhos artificiais em fragmentos de matas do Brasil Central. Ornitologia Neotropical. 1997; 8:7-14.

20. Small MF, Hunter ML. Forest fragmentation and avian nest predation in forested landscapes. Oecologia. 1988; 76:62-64.

21. Barbini IG, Passamani M. Pequenos mamíferos e a predação de ninhos artificiais no Museu de Biologia Prof. Mello Leitão (ES). Natureza on line. [on line] 2003; 1(2):56-61. [capturado em 08 de janeiro de 2006] Disponível em: URL: http:// naturezaonline.com.br.

22. Roos S. Functional response, seasonal decline and landscape differences in nest predation risk. Oecologia. 2002; 133:608-615.

23. Martin JL, Joron M. Nest predation in forest birds: influence of predator type and predator's habitat quality. Oikos. 2003; 102:641-653.

24. Martin TE, Roper JJ. Nest predation and nest size selection of a western population of Hermit Thrush. Condor. 1988; 90:51-57.

25. Reistma LR, Holmes RT, Sherry TW. Effects of removal of red squirrels, Tamia hudsonicus, and castern chipmunk, Tamias striatus, on nest predation in a northern hardwood forest: an artificial nest experiment. Oikos. 1990; 57:375380.

Recebido em: 15.02.2006

Aceito em: 24.03.2006 